\title{
A POTENCIALIDADE DA LITERATURA NA AQUISIÇÃO DE LINGUAGEM
}

\section{Cristiane Fernandes Almeida ${ }^{1}$ Maria Helena Nunes de Jesus ${ }^{2}$ \\ Vanessa Larissa de Andrade ${ }^{3}$ Juliane Rocha de Moraes ${ }^{4}$}

Resumo: O presente trabalho busca esclarecimentos sobre uma grande potencialidade que a literatura possui para o processo da aquisição da linguagem. Baseia-se os estudos em pesquisas bibliográficas de autores, assim, compreende-se o verdadeiro significado que os periódicos infantis contribuem positivamente para o despertar e o desejo nas crianças pela leitura de diversos textos, auxiliando também na alfabetização, desenvolvendo uma postura adequada e coerente para se comunicar, se expressar e compreender como no papel de leitor, através das práticas de escolhas de bons livros. A literatura infantil dificilmente é lugar de destaque, quando possui apenas função visual ou puramente mecânica. Não deve ser momento de manuseio, mas sim de interação, criatividade, imaginação, emoções de formas significativas.

Palavras-chave: Aquisição; Estímulo; Infantil; Literatura; Livro.

\footnotetext{
1 Pós- Graduação em Alfabetização/INESP, Brasil. E-mail: cguiomar2014@bol.com.br.

2 Pós- Graduação em Alfabetização/INESP, Brasil. E-mail: vlandrade.profissional@gmail.com.

3 Pós- Graduação em Alfabetização/INESP, Brasil. E-mail: mariahelenan.7@gmail.com.

4 Pós- Graduação em Alfabetização/INESP, Brasil. E-mail: juli04.rocha@gmail.com.
} 